\title{
DESENVOLVIMENTO DE INSTRUMENTO MUSICAL DE CORDAS: UKULELE
}

\author{
Ana Luiza Seeger Guerra \\ anaseeg@gmail.com \\ Pedro Henrique Azevedo \\ pedrohazevedo94@gmail.com \\ Mariana Piccoli \\ marianap.piccoli@gmail.com
}

Resumo: Este artigo apresenta o processo de criação de um instrumento musical de cordas, o ukulele, baseada na técnica de personas e relata sua produção nas instalações do Curso de Desenho Industrial da UFSM. O conceito que se pretendeu atingir no desenvolvimento do instrumento foi baseado no equilíbrio e na simplicidade. Já a temática escolhida foi o Havaí, que se caracteriza, principalmente, pela sua natureza - praias, montanhas, vulcões. Imagens foram selecionadas e criaram-se painéis visuais da temática e da expressão do produto. Para orientação do projeto, o processo de trabalho baseia-se na metodologia da Empresa Júnior de Desenho Industrial, a Projetar. Esta metodologia foi escolhida por possuir um caráter flexível, podendo ser utilizada conforme as necessidades de cada projeto. O projeto é composto por um instrumento musical, sendo realizado um mocape não funcional deste como forma de representação. O processo se deu por meio de equipamentos da marcenaria e o acabamento foi realizado manualmente pelos autores. Acredita-se que se tenha atingido o objetivo do projeto com este produto, sendo sua forma adaptada à persona escolhida, assim como se enquadrando à temática e ao conceito.

Palavras-chave: Design; música; instrumento musical. 


\section{INTRODUÇÃO}

"Design, assim como inovação tecnológica, é elemento gerador de mudanças." (PUERTO, 1999, p.13)

Segundo Brandi (2011), tratando-se da evolução da cultura objetual, o desenhista industrial é um profissional habilitado para interferir no desenho e projeto do produto em questão, aprimorando e inclusive atualizando-o formalmente. Além de contribuir para criar acultura material da vida cotidiana de uma sociedade, ele atua como agente transformador.

Com base nesta afirmação e com o conhecimento obtido no Laboratório Profissionalizante de Equipamentos, este artigo apresenta o redesenho de um instrumento musical de cordas - o ukulele - baseada em uma temática e conceito, descrevendo todo o seu processo de concepção formal e produção. Inicialmente apresenta-se a metodologia empregada, a temática escolhida e o conceito. A concepção formal é demonstrada com imagens relativas ao processo e a evolução de geração de alternativas. Também se explica todo o processo de produção adotado neste projeto, assim como seus resultados.

\section{DESENVOLVIMENTO}

Para orientação do projeto, o processo de trabalho baseia-se na metodologia da Empresa Júnior de Desenho Industrial, a Projetar. Esta metodologia foi escolhida por possuir um caráter flexível, podendo ser utilizada conforme as necessidades de cada projeto, tanto gráfico como visual.

\subsection{Eddie Vedder}

Um mapa mental, segundo Pazmino (2015):

[...] Trata-se de uma estratégia na organização de ideias por meio de palavras-chave, cores, imagens, símbolos, figuras, em uma estrutura que se irradia a partir de uma ideia, um conceito, um conteúdo. [...] O mapa mental é o reflexo dos processos e capacidades de pensamento tanto naturais como imagéticos do cérebro. $\mathrm{Na}$ montagem de um mapa mental deve-se sempre considerar a ideiacentral e completá-la com uma sequência de ideias, com ramos curvos, orgânicos como os galhos de uma árvore. (PAZMINO, 2015).

Com essa definição em mente, criou-se um mapa mental considerando-se o artista Eddie Vedder como ideia-central (figura 1).

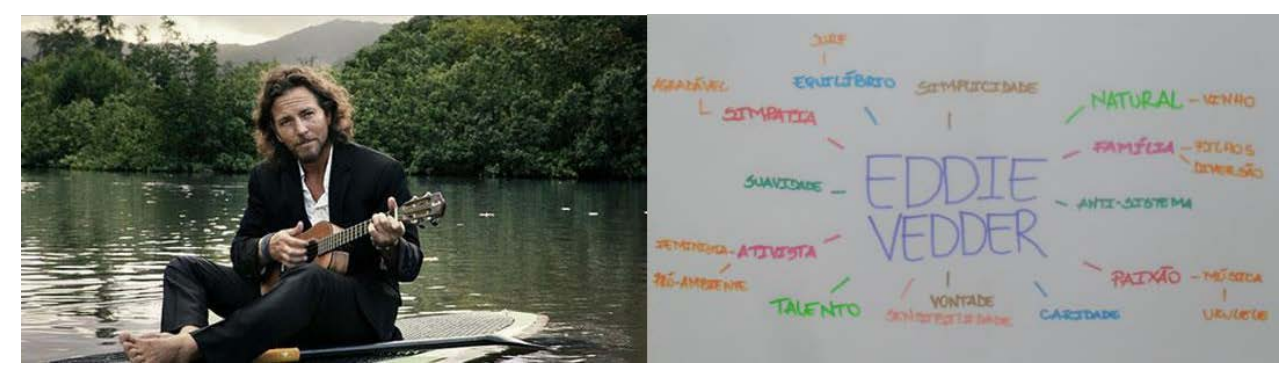

Figura 1 - Eddie Vedder e mapa mental.

Fonte: Adaptado do Google imagens e elaborada pelos autores com base na pesquisa realizada. 


\subsection{Ukulele}

A estrutura do ukulele pode ser dividida em quatro partes: corpo, cordas, tarraxas e casas (figura 2). O corpo do ukulele é a parte principal do instrumento, sendo a parte da frente (o tampo) a mais importante para a qualidade do som. Por este motivo há utilização de madeira mais nobre nessa parte posterior do corpo. Já as demais paredes do corpo do ukulele (lateral e fundo) costumam ser feitas com materiais menos nobres, variando de madeiras de menor preço até polímeros. A madeira mais utilizada no Havai é a koa havaiana.

Já as cordas são linhas de nylon ou metal que se localizam ao longo do braço até certa parte do corpo. Elas são necessárias para tocar de fato o instrumento. Ao dedilhar/tocar as cordas criam-se vibrações que são transmitidas por meio do orifício localizado na parte posterior do ukulele (a boca) para o interior do corpo, em que este funciona como uma caixa de ressonância para o som. Cordas de qualidade são parte importante para se atingir uma boa qualidade de som do instrumento.

As cordas são presas na parte inferior pelo cavalete e o rastilho e na parte superior pelas tarraxas. Estas permitem a afinação do instrumento. A pestana localizase entre a mão e o braço e permite a acomodação adequada das cordas. No braço também se localizam as casas, que são os lugares destinados para a execução dos acordes com a mão esquerda para destros e com a mão direita para canhotos.

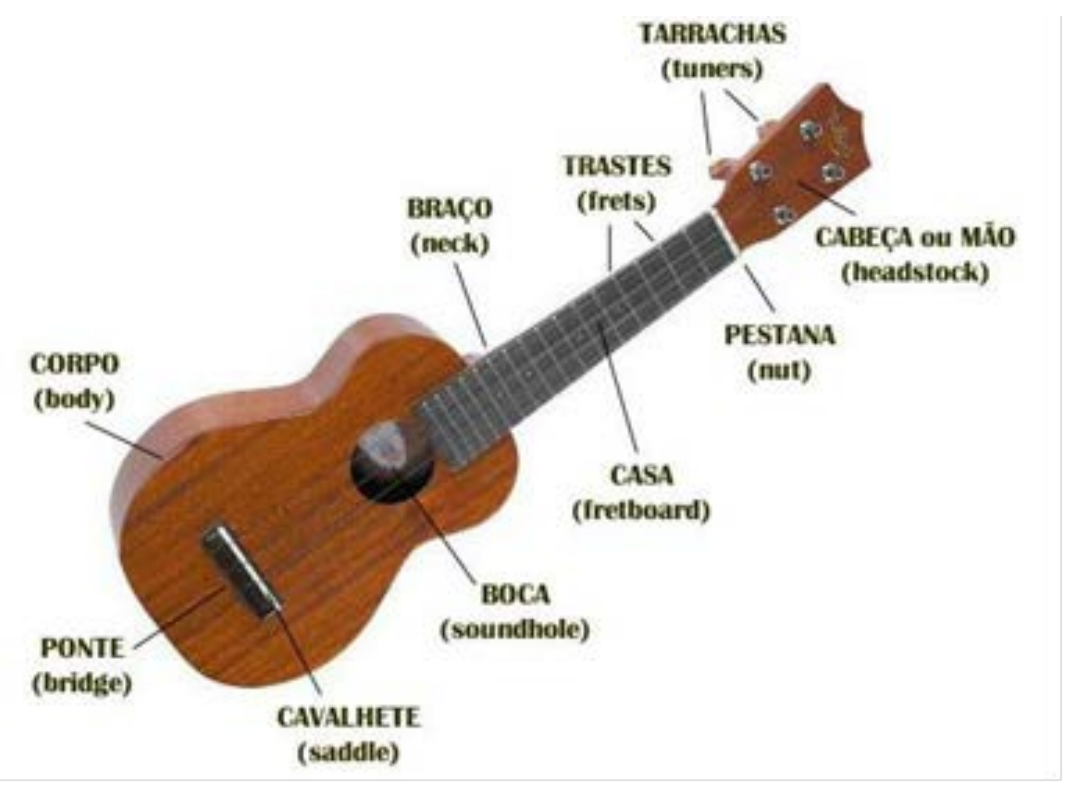

Figura 2 - Partes do Ukulele.

Fonte: Elaborado pelos autores, com base na pesquisa realizada.

\subsection{Lista de requisitos}

Com base nas análises e nas características da persona, pôde-se criar a lista de requisitos (quadro 1) que se pretendeu atingir com este projeto. Essa lista serve como referência para várias decisões que culminarão nas características do produto projetado. Esses requisitos foram classificados em desejáveis e obrigatórios e foram revisados ao final do projeto, como forma de validação do resultado. 
Quadro 1 - Lista de requisitos que pretendeu se atingir com este projeto.

\begin{tabular}{|c|c|c|}
\hline & OBRIGATÓRIO & DESEJÁVEL \\
\hline Requisitos de uso & $\begin{array}{l}\text { Facilidade de uso; } \\
\text { Ergonomia durante o uso; Fácil } \\
\text { afinação; } \\
\text { Não causar incômodo durante o } \\
\text { uso; }\end{array}$ & Afinação das cordas facilitada; \\
\hline $\begin{array}{l}\text { Requisitos de } \\
\text { função }\end{array}$ & $\begin{array}{l}\text { Boa reverberação; } \\
\text { Fácil transporte; }\end{array}$ & Resistência ao impacto; \\
\hline $\begin{array}{l}\text { Requisitos } \\
\text { estruturais }\end{array}$ & $\begin{array}{l}\text { Diminuição do número de } \\
\text { peças; } \\
\text { Redução de materiais utilizados; }\end{array}$ & $\begin{array}{l}\text { Mudança no formato; } \\
\text { Junção por encaixe; Privilegiar } \\
\text { materiais de procedência } \\
\text { ecológica, certificados, } \\
\text { biodegradáveis, leves, locais, } \\
\text { renováveis e abundantes; }\end{array}$ \\
\hline $\begin{array}{l}\text { Requisitos técnicos- } \\
\text { produtivos }\end{array}$ & $\begin{array}{l}\text { Necessidade de pouca } \\
\text { manutenção; Minimizar resíduos; } \\
\text { Processo produtivo menos } \\
\text { agressivo ao ambiente; }\end{array}$ & $\begin{array}{l}\text { Materiais alternativos; } \\
\text { Minimizar materiais tóxicos e } \\
\text { permanentes; }\end{array}$ \\
\hline Requisitos formais & $\begin{array}{l}\text { Forma adequada à função; } \\
\text { Aparência condizente com a } \\
\text { semântica; }\end{array}$ & \\
\hline $\begin{array}{l}\text { Requisitos de } \\
\text { identidade }\end{array}$ & Aparência natural. & $\begin{array}{l}\text { Identificar a finalidade do } \\
\text { produto: ukulele. }\end{array}$ \\
\hline
\end{tabular}

Fonte: Elaborado pelos autores com base na pesquisa realizada.

\subsection{Projeto conceitual}

\subsubsection{Diferencial Semântico}

O diferencial semântico (figura 3) é uma técnica que permite ajudar no desenvolvimento do produto, pontuando características opostas, sendo que estes valores buscam representar o produto pretendido. Geralmente é respondido pelo público-alvo que se pretende atingir, porém, neste caso foi classificado pelos autores de acordo com a persona.

Conforme a avaliação, o produto procurou atender principalmente características de simplicidade e clareza. Esta última refere-se à clareza das informações necessárias para se identificar um ukulele, assim como clareza ao usar o produto. 


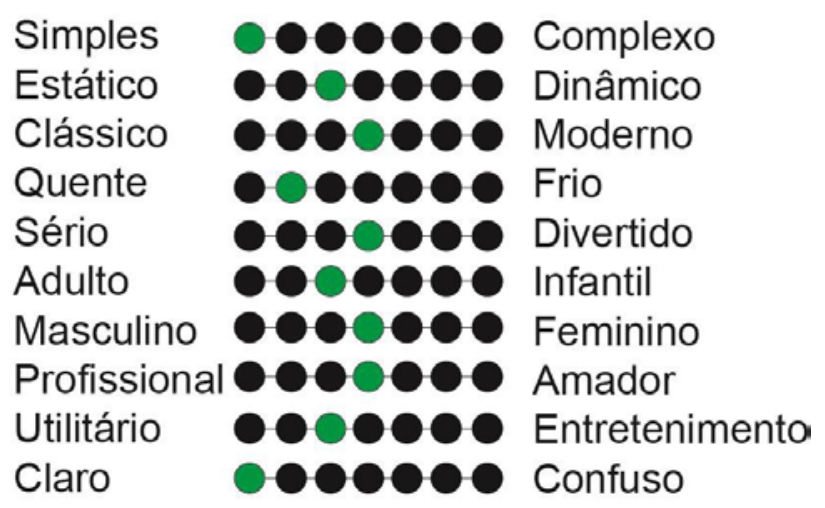

Figura 3 - Diferencial semântico.

Fonte: Elaborado pelos autores, com base na pesquisa realizada.

\subsubsection{Expressão}

"A partir do estilo de vida, procura-se identificar uma expressão de valor para o produto. Essa expressão deve ser uma síntese de estilo de vida dos consumidores. Ela representa a emoção que o produto transmite ao primeiro olhar." (SOUZA, 2011).

Baseando-se nas características da persona escolhida e no resultado do diferencial semântico, a expressão do produto (figura 4) procurou representar o equilíbrio e a simplicidade.

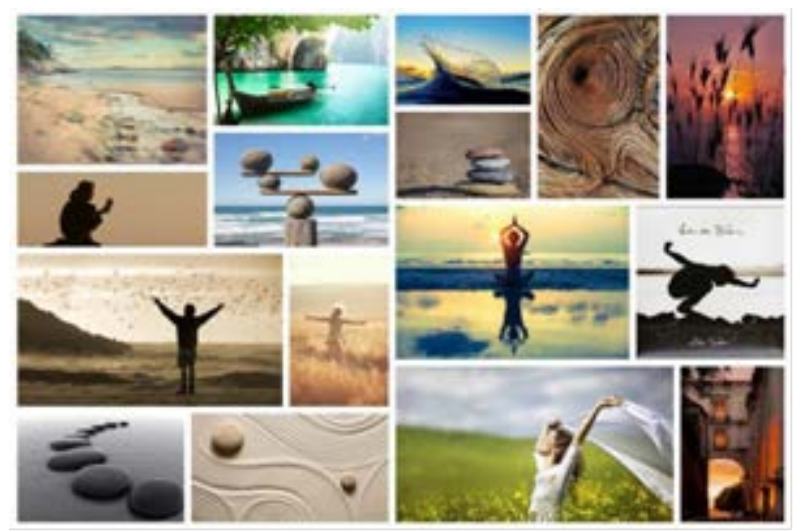

Figura 4 - Expressão do produto.

Fonte: Adaptado do Google imagens.

\subsubsection{Temática: Havaí}

"A partir do painel de expressão do produto, organiza-se o painel do tema visual, juntando-se imagens de produtos que estejam de acordo com o espírito pretendido para o novo produto." (SOUZA, 2011).

O tema escolhido foi o Havaí (figura 5), pois, além de ser o local de origem do ukulele, se enquadra nas características mais importantes obtidas do diferencial semântico, além de lembrar características pessoais da própria persona (simples e ecológico). 


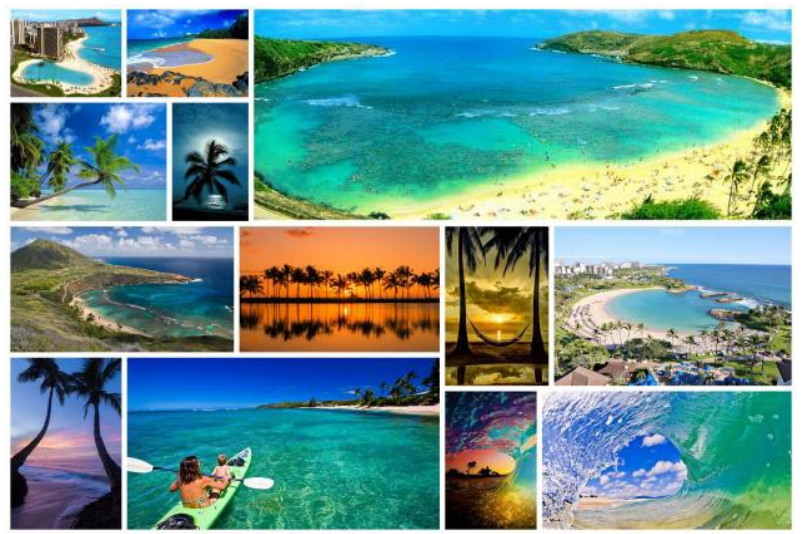

Figura 5 - Temática do produto.

Fonte: Adaptado do Google imagens.

\subsection{Concepção formal}

A geração de alternativas é a produção de um conjunto de ideias para solucionar um problema. Essas ideias, quando melhor pensadas/esboçadas, geram alternativas. Primeiramente houve uma extração de linhas dos painéis temático e de expressão. Após esse procedimento, uma caixa morfológica foi montada com essas formas, havendo o cruzamento dessas linhas, gerando uma maior variedade formal.

Com base nas formas existentes na caixa morfológica, partiu-se para uma geração de alternativas livre, buscando semelhanças nos painéis temáticos e de expressão, criando-se transformações adaptativas das formas obtidas dos painéis a fim de aumentar a variedade de soluções (figura 6).

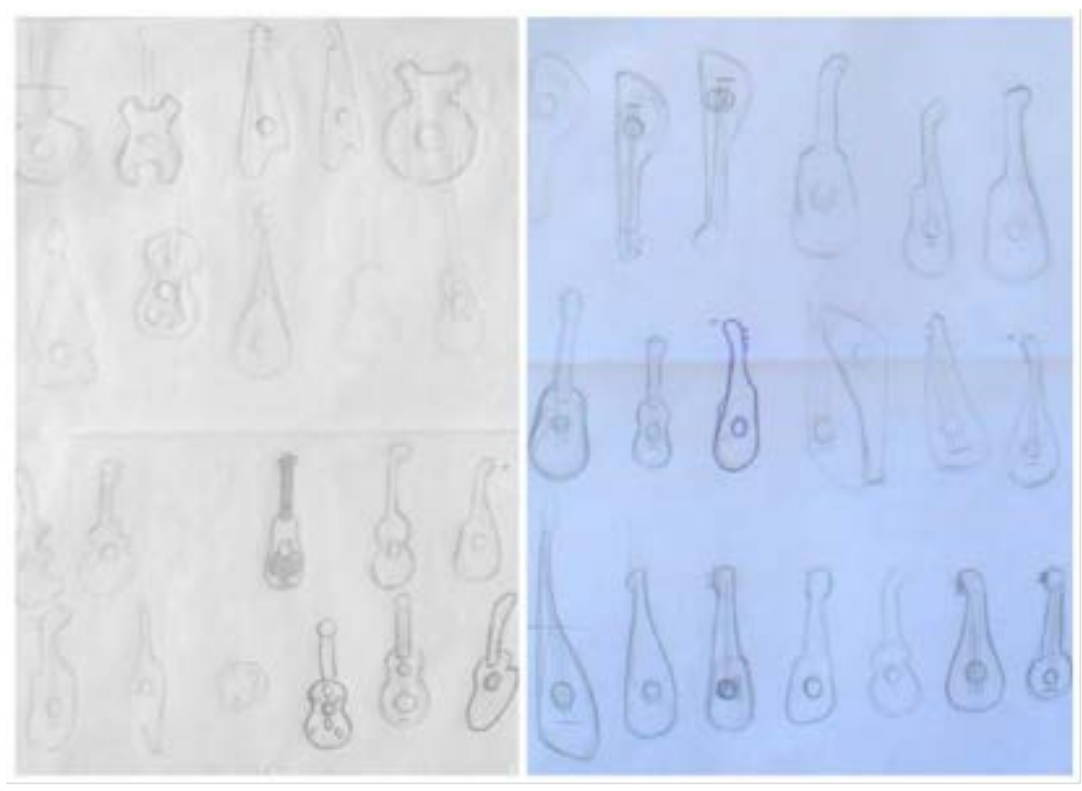

Figura 6 - Últimas alternativas com base na caixa morfológica.

Fonte: Elaborado pelos autores, com base na pesquisa realizada.

Após, reuniu-se todas as alternativas geradas e analisaram-se as características positivas e negativas de cada uma. Algumas alternativas foram selecionadas e modeladas em pequena escala em clay, para uma melhor visualização tridimensional 
da forma. Por fim, escolheu-se a alternativa que mais se enquadrou no conceito, sendo refinada (figura 7 ) e modelada em mocape volumétrico para testes (figura 8).

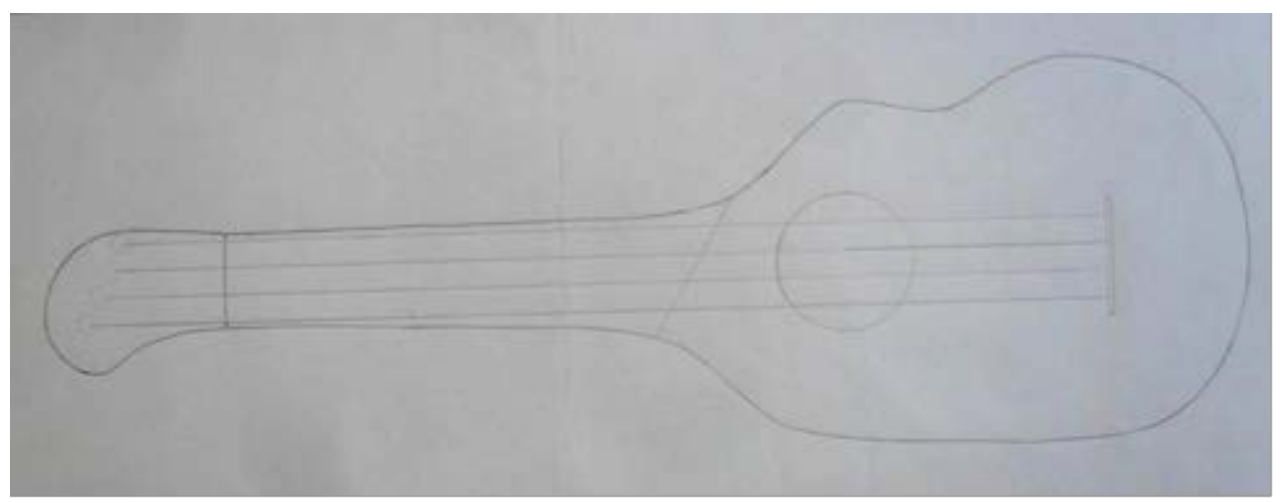

Figura 7: Alternativa selecionada após o processo de refinamento.

Fonte: Elaborado pelos autores, com base na pesquisa realizada.

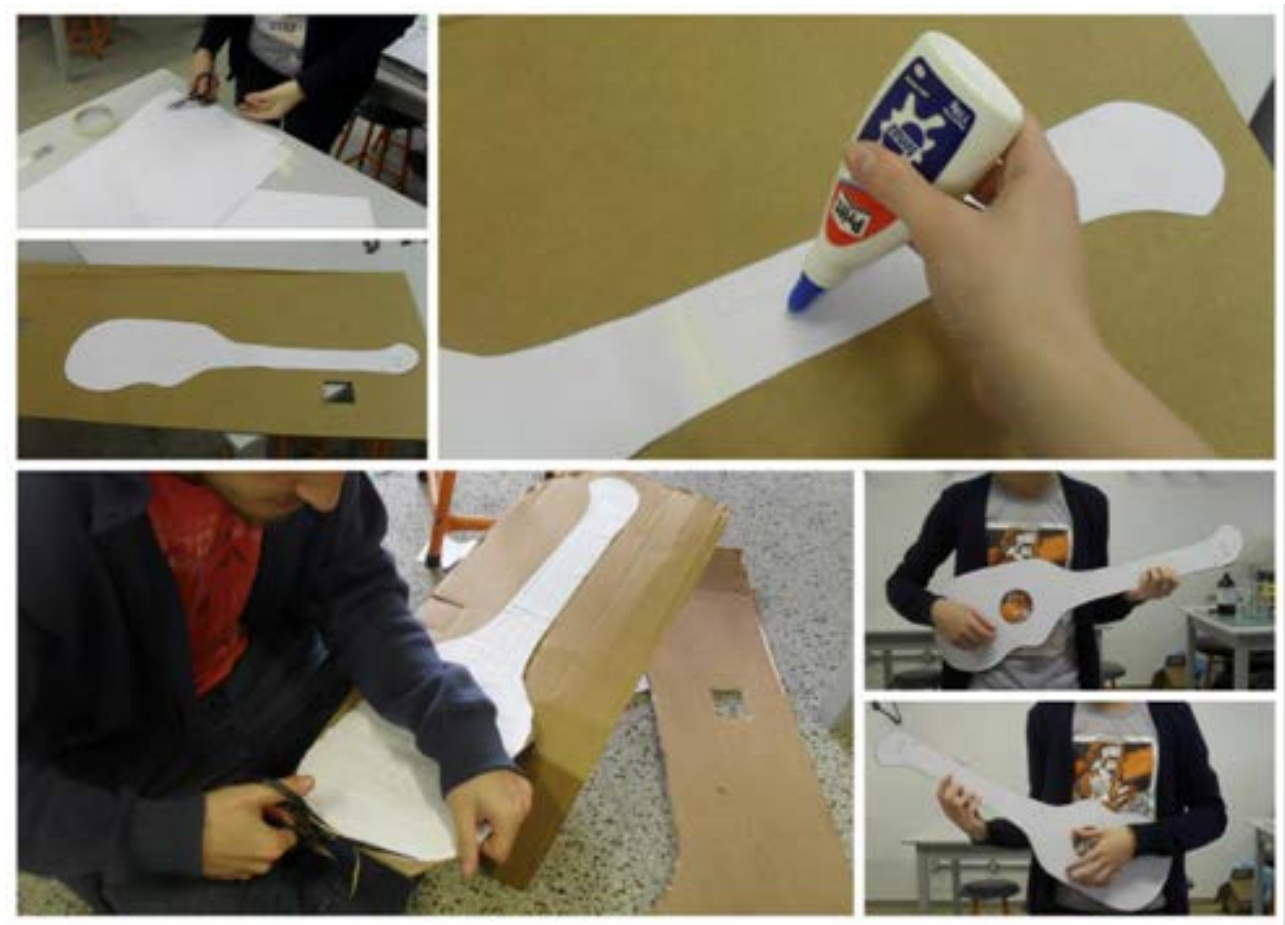

Figura 8: Refinamento da forma do instrumento e testes volumétricos para possibilidade de uso de canhotos e destros.

Fonte: Elaborado pelos autores, com base na pesquisa realizada.

\subsection{Produção}

O mocape foi produzido em madeira de pinus (Pinus elliottii Engelm., Pinaceae), uma madeira de baixo custo e com baixa qualidade para aplicações em instrumentos (figura 9). Porém, este material foi usado como forma de simulação do material final. A sugestão dos autores sobre o material a ser utilizado no protótipo do instrumento é a de utilização de madeira reciclada e/ou de madeiras legais, preferencialmente da região onde o produto for produzido ou madeiras provenientes de reflorestamento. 


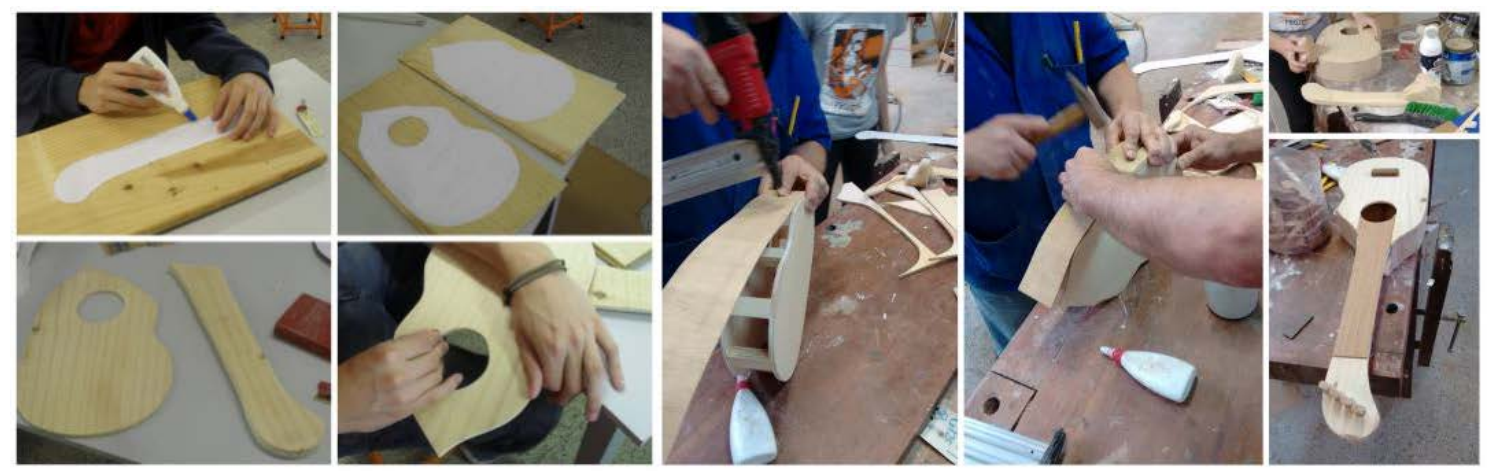

Figura 9: Processo de produção do mocape.

Fonte: Elaborado pelos autores, com base na pesquisa realizada.

\subsection{Resultados}

A seguir, o resultado final é apresentado (figura 10) juntamente com os painéis temático e de expressão e a avaliação da lista de requisitos. Acredita-se que o produto final esteja em coerência com a linguagem visual dos painéis (figura 11).

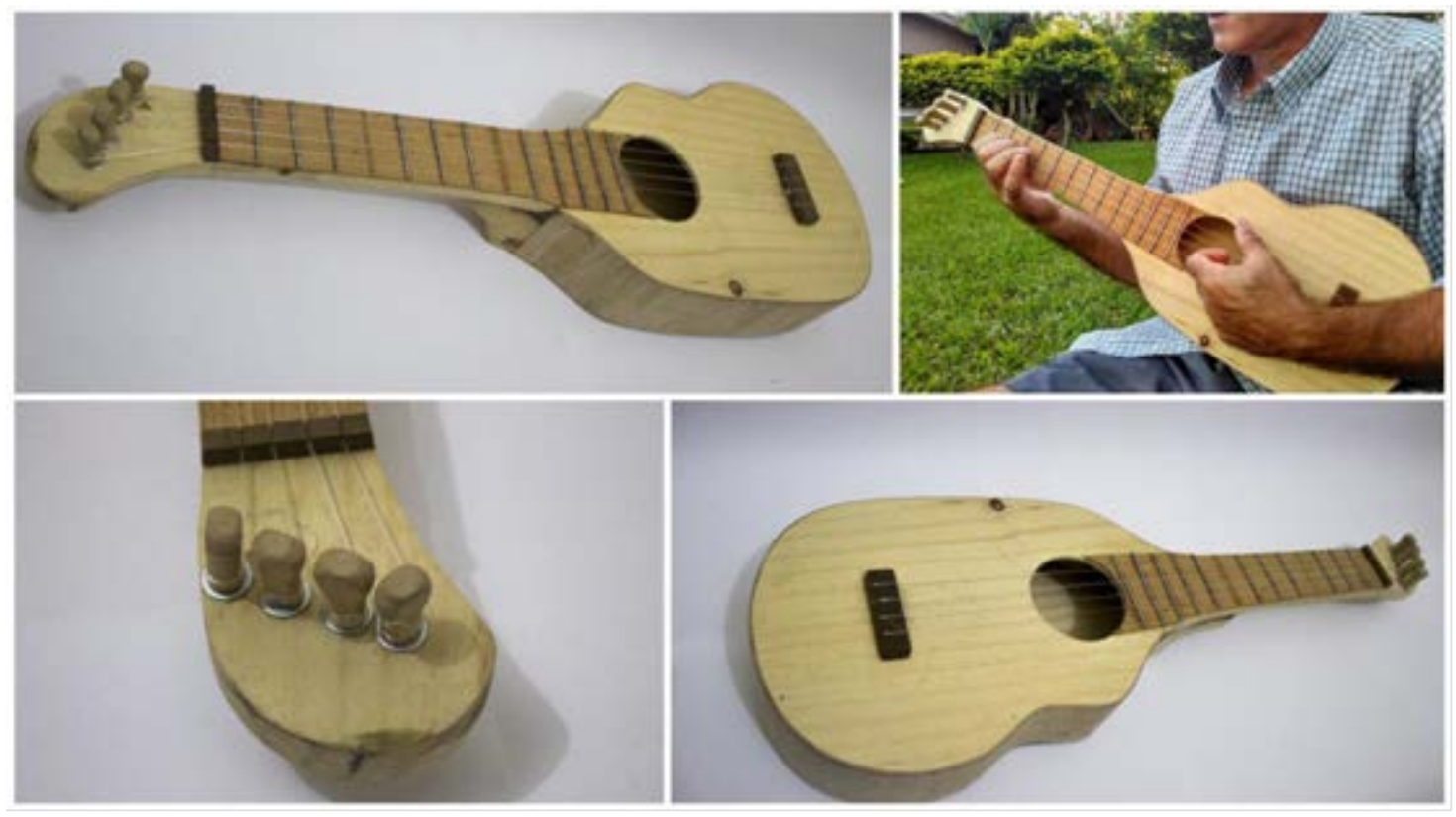

Figura 10: Mocape do ukulele finalizado.

Fonte: Elaborado pelos autores, com base na pesquisa realizada. 

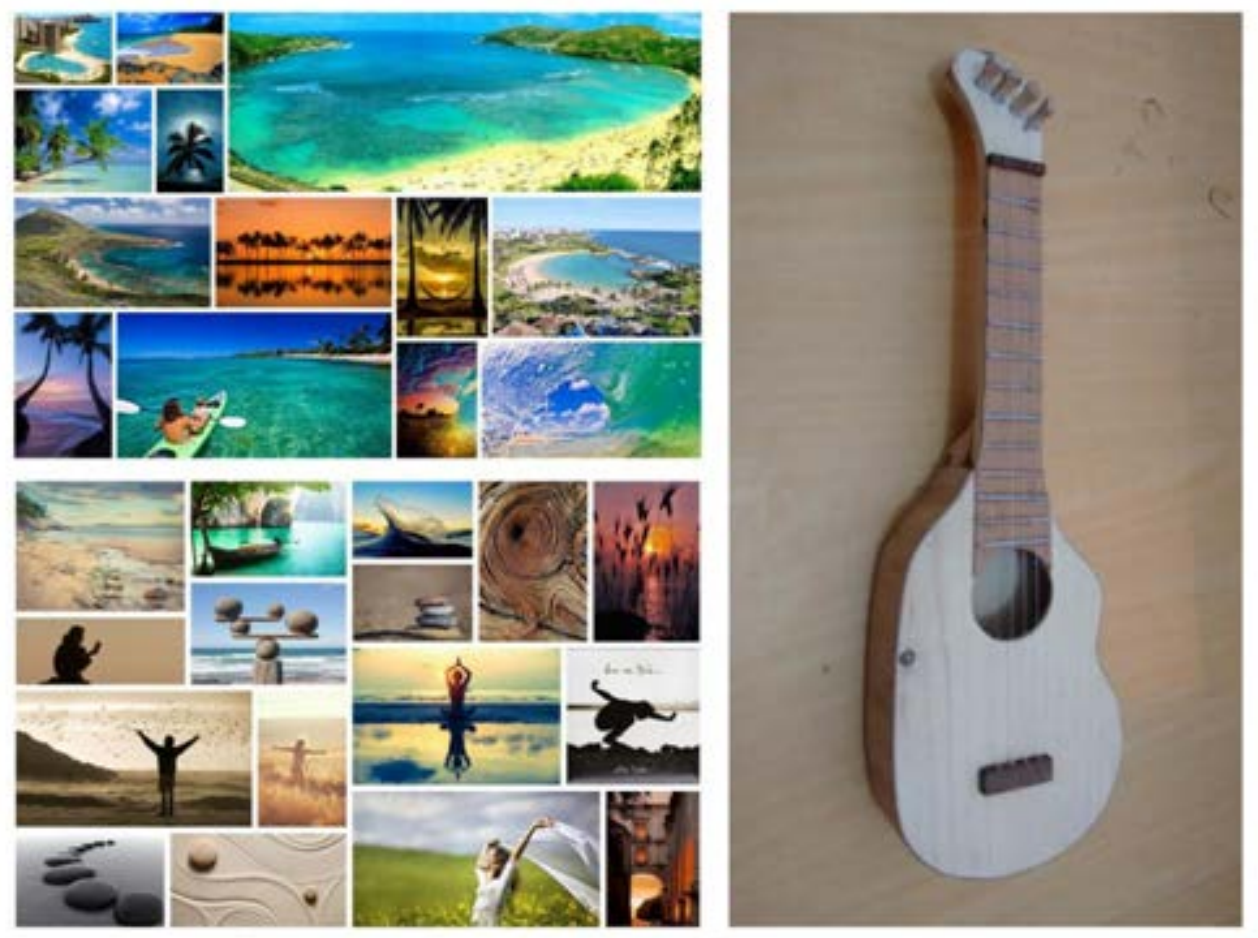

Figura 11: Mocape do ukulele finalizado.

Fonte: Elaborado pelos autores, com base na pesquisa realizada.

Quanto à avaliação da lista de requisitos, fez-se uma escala e valores com as variantes "atingido", "atingido parcialmente", "não atingido" e "não se sabe", sendo este último referente aos requisitos que não puderam ser avaliados pois não se criou o protótipo do produto. São estes: boa reverberação, resistência ao impacto, necessidade de pouca manutenção e privilegiar materiais de procedência ecológica, certificados, biodegradáveis, leves, locais, renováveis e abundantes. A maioria dos requisitos estabelecidos foi atingida com eficiência.

Em função do curto prazo destinado ao projeto de redesenho ukulele, o requisito junção por encaixe não foi atingido, sendo que a elaboração de um sistema de encaixe demandaria muito tempo para ser projetada. A afinação das cordas facilitada foi avaliada como requisito parcialmente atingido, pois não se projetou um sistema inovador de afinação, apenas a afinação foi facilitada pois a posição das tarraxas está num local estratégico e de fácil acesso, na mão do ukulele. O mesmo aconteceu com a diminuição do número de peças e a minimização de resíduos, sendo parcialmente atingidos.

\section{CONCLUSÃO}

Ao final do trabalho obteve-se um mocape volumétrico não funcional do instrumento ukulele, sendo suas formas resultantes da caixa morfológica derivada da extração de linhas dos painéis de expressão e temático. Estes painéis foram criados a partir de expressões verbais retiradas do mapa mental que teve como ideia central a persona (representação de um público-alvo em um único ser), o artista Eddie Veeder. Como embasamento teórico do projeto, realizaram-se diversas análises - diacrônica, 
sincrônica, estrutural, funcional, etc. - que foram fundamentais para se entender o universo do produto.

Uma lista de requisitos foi elaborada e serviu como guia do projeto, sendo revisada após a conclusão do projeto, servindo de validação do projeto pois se atingiram a maioria dos requisitos obrigatórios suficientemente. Pelo tempo de duração do projeto não se pôde validar algumas variáveis como a resistência ao impacto e a reverberação. Porém, estas questões podem servir de inspiração para próximos trabalhos elaborados no Laboratório de Equipamentos do curso de Desenho Industrial, visto que é o segundo semestre que esta disciplina possui essa abordagem do novo currículo do curso.

\section{REFERÊNCIAS}

BRANDI, Leonardo Barili. Projeto de guitarra baseado em inovação incremental. Santa Maria, RS, 2011.

HAVAÍ: Localização, ilhas, praias, turismo, economia, geografia, surf, foto.

Disponível em: <http://www.suapesquisa.com/pesquisa/havai.htm>. Acesso em: 10 out. 2015.

History of the Ukulele - 'Apanhei-te Cavaquinho'. Produção RTP 2. Disponível em: < https://www.youtube.com/watch?v=bG_plcFHzpc >. Acesso em: 5 out. 2015.

PAZMINO, Ana Veronica. Como se cria: $\mathbf{4 0}$ métodos para Design de Produtos. São Paulo: Blucher, 2015.

PUERTO, Henry Benavides. Design e inovação: coletânea de idéias para construir um discurso. Salvador: Gráfica Envelope e Cia, 1999.

SOUZA, Francis Martins de. Metodologia de Projeto II. Faculdade de Tecnologia de Birigui - FATEB. Birigui, 2011.

Imagens: Google imagens. Disponível em:

$<$ https://www.google.com.br/imghp?hl=pt- PT>.Palavras-chave:

<eddievedder $><$ equilíbrio $><$ havaí $><$ hawaii $><$ simplicidade $><$ ukulele $>$ 